J-SISKO TECH

Jurnal Teknologi Sistem Informasi dan Sistem Komputer TGD

P:ISSN : 2621-8976 E-ISSN : 2615-5133

Vol.3, No.1, Januari 2020, pp.32-40

\title{
Implementasi Teknik Komunikasi Serial Half Duplex Pada Kendali Jarak Jauh Lampu Ruangan Rumah Berbasis Internet Of Things (IOT)
}

\author{
*Jaka Prayudha, Ardianto Pranata, Heru Prastyo \\ Program Studi Sistem Komputer, STMIK Triguna Dharma \\ Jl. A.H Nasution No.73 Medan, Indonesia, 20142 \\ E-mail: jakaprayudha3@gmail.com
}

\begin{abstract}
Abstrak
Lampu listrik adalah suatu perangkat elektronika yang dapat menghasilkan cahaya pada saat dialiri arus listrik. Di zaman modern ini, lampu listrik sangat berguna sekali bagi kehidupan manusia. Dengan lampu listrik setiap orang dapat melihat di kegelapan pada saat malam hari atau pada saat cuaca sudah mulai gelap sekali. Internet of Things atau disingkat juga dengan IoT adalah sebuah konsep yang bertujuan memanfaatkan dan memperluas konektivitas internet yang tersambung secara terus-menerus untuk bisa terhubung di semua perangkat elektronika. Dengan demikian dibutuhkan suatu sistem yang dapat mengendalikan hidup matinya lampu ruangan rumah dari jarak dekat maupun jauh dengan memanfaatkan konsep Internet of Things. Sistem kendali jarak jauh lampu ruangan rumah di rancang menggunakan NodeMCU Esp8266 sebagai sistem pengontrol dan pembaca jaringan wifi, relay yang berfungsi sebagai saklar logika yang menerima perintah dari NodeMCU Esp8266 untuk mengatur kendali lampu menyala atau padam. Aplikasi Telegram berfungsi sebagai platform dalam pengiriman data atau perintah ke NodeMCU Esp8266. Sistem ini dapat mengendalikan hidup matinya lampu dari jarak dekat maupun jauh berdasarkan perintah user melalui aplikasi telegram ke NodeMCU Esp8266. Sistem kendali lampu ruangan rumah menggunakan teknik Komunikasi Serial Half Duplex sebagai mode aliran data dan teknik perhitungan untuk mengkonversi nilai apapun ke biner.
\end{abstract}

Kata kunci : NodeMCU Esp8266 Devkit 3, Teknik Half Duplex, Relay Lampu

\begin{abstract}
An electric lamp is an electronic device that can produce light when electrified. In modern times, electric lights are very useful for human life. With electric lights anyone can see in the dark at night or when the weather is getting very dark. Internet of Things or abbreviated also with loT is a concept that aims to utilize and expand internet connectivity that is connected continuously to be able to connect on all electronic devices. Thus we need a system that can control the life and death of home room lights from close and far distances by utilizing the concept of the Internet of Things. The remote control system for home room lights is designed to use NodeMCU Esp8266 as a controller and wifi network reader system, a relay that functions as a logic switch that receives commands from NodeMCU Esp8266 to regulate the lights on or off. The Telegram application functions as a platform for sending data or orders to NodeMCU Esp8266. This system can control the life of the death of the lamp from close or far distance based on user orders via the telegram application to NodeMCU Esp8266. Home room lighting control systems use the Half Duplex Serial Communication technique as a data flow mode and calculation technique to convert any value to binary.
\end{abstract}

Keywords: NodeMCU Esp8266 Devkit 3, Half Duplex Technique, Lamp Relay 


\section{PENDAHULUAN}

Di era globalisasi ini mobilitas manusia sangatlah meningkat dalam pekerjaan, kehidupan sehari-hari dan segala jenis aktivitas yang lain terutama di daerah perkotaan. Dalam hal bepergian kemana saja dilakukan menggunakan alat transportasi pribadi maupun alat transportasi umum seperti mobil, bus dll. Hal-hal ini yang menyebabkan daerah perkotaan sangat mudah terjadi kemacetan lalu lintas yang merupakan masalah yang serius apalagi terjadi di jam-jam tertentu seperti pada waktu-waktu jam pulang kerja sehingga menyebabkan keterlambatan sampai di rumah terlalu larut malam. Apalagi jika kondisi penerangan rumah yang memiliki beban lampu yang sangat besar yang membuat pembayaran listrik sangat mahal sehingga tidak efisien jika penerangan lampu selalu dinyalakan dari siang hari hingga malam hari apalagi jika para penghuni tidak ada di rumah karena sekeluarga bepergian keluar kota untuk rekreasi atau melakukan kegiatan lain. Berdasarkan masalah ini, maka lampu penerangan rumah harus dinyalakan di jam-jam tertentu menjelang gelap. Tapi jika para penghuni rumah tidak ada di tempat, perlu kiranya untuk menyalakan dan mematikan lampu dapat dengan mudah diakses memalui jarak yang jauh dengan biaya yang tidak terlalu mahal, mudah dan efisien seperti menggunakan komunikasi media Internet of Things (IoT).

\section{METODE PENELITIAN}

Half duplex merupakan sebuah metode pengirim dan penerima data agar dapat saling berbagi informasi dan komunikasi tetapi secara tidak bersamaan. Dalam komunikasi data dengan half duplex, teks dipresentasikan sebagai pola bit dan urutan bit. Pola set bit yang berbeda telah dirancang untuk mempresentasikan simbol teks. Setiap set disebut kode dan proses yang mempresentasikan simbol-simbol disebut coding. Dalam pengiriman data teks hanya nilai biner yang di pahami oleh smartphone dan NodeMCU Esp 8266 maka dari itu akan terjadi perubahan nilai ketika melakukan pengiriman data. Contoh alat komunikasi yang memanfaatkan metode teknik half duplex ini adalah walkie-talkie. Dimana salah satu penggunanya harus menekan tombol terlebih dahulu baru kemudian berbicara, sementara pihak lain mendengarkan. Jika kedua-duanya mencoba untuk berbicara secara serentak maka kondisi "collision" (tabrakan) pun terjadi kedua pengguna walkie-talkie tersebut tidak saling dapat mendengarkan apa yang dikirimkan.

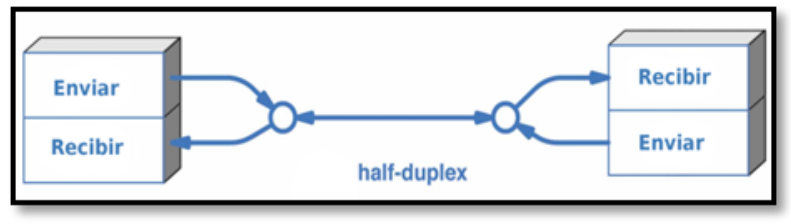

Gambar 1 Teknik Pengiriman Data Half Duplex

\section{ANALISA DAN HASIL \\ 3.1. Analisis Permasalah}

Sistem yang akan dibangun pada skripsi ini bermula dari ide mengenai permasalahan penerangan lampu rumah ketika para penghuni tidak berada di rumah. Salah satu permasalahan yang muncul ketika hari memasuki jam-jam malam dan penghuni rumah tidak berada di tempat yang menyebabkan lampu penerangan rumah masih terlihat gelap. Hal inilah yang dapat mengakibatkan sering terjadinya tindakan kriminal seperti mencuri karena rumah masih terlihat gelap di malam hari. Tentu saja hal ini membuat pemilik rumah mengalami kerugian besar karena barang-barang berharga telah dicuri. Jika pemilik rumah menyalakan lampu rumah dari siang hingga malam hari karena harus pulang larut malam bekerja atau pergi jalan-jalan dengan keluarga hal ini dapat mengakibatkan naiknya pembayaran listrik tiap bulannya. Untuk itu dibutuhkan suatu sistem yang dapat membantu pemilik rumah dalam menghadapi dan mengatasi masalah tersebut. Salah satunya adalah dengan cara menambahkan sistem loT (Internet of Things) pada kendali lampu jarak jauh agar pemilik rumah dapat mengkontrol penerangan rumahnya jika sedang tidak berada di tempat. 
Algoritma sistem adalah bagan alir dari proses kerja sistem yang merupakan aliran keluaran untuk input dan output. Algoritma sistem merupakan suatu urutan atau tahapan proses dari sistem yang logis guna menyelesaikan masalah, tugas dan fungsinya. Dimana penentuan algoritma yang ditentukan tiap-tiap penyusunan sistem berdasarkan kejadian dari penilaian awal dan dilanjutkan dengan penilaian akhir secara logis pada sistem untuk memaksimalkan kinerja pada sistem yang ingin dijalankan.

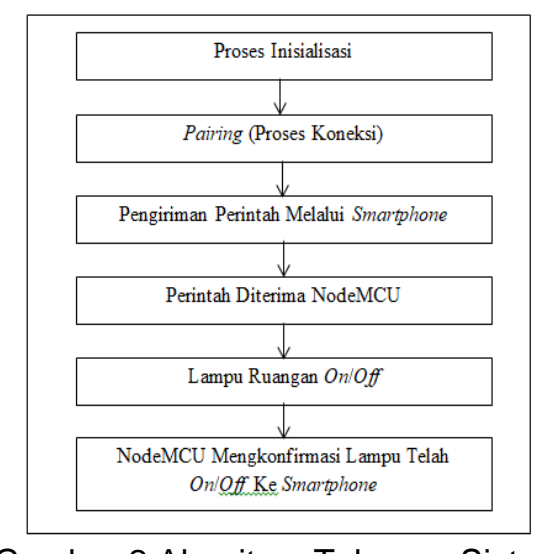

Gambar 2 Algoritma Tahapan Sistem

Pada sistem ini menggunakan aplikasi telegram messeger sebagai platform dalam pengiriman data teks ke NodeMCU Esp8266. Dalam pengiriman data teks hanya nilai biner yang di pahami oleh smartphone dan NodeMCU Esp 8266 maka dari itu akan terjadi perubahan nilai ketika melakukan pengiriman data. Berikut adalah salah satu contoh pengiriman data dari telegram ke NodeMCU Esp8266 dengan teks "LampuTerasOn" adalah sebagai berikut :

Tabel 1 Konversi Nilai Dari Teks "LampuTerasOn"

\begin{tabular}{|c|c|c|c|c|}
\hline \multirow{2}{*}{ Karakter } & \multicolumn{4}{|c|}{ Konversi Nilai } \\
\cline { 2 - 5 } & ASCII & Hexadesimal & Desimal & Biner \\
\hline / & $/$ & $2 \mathrm{~F}$ & 47 & 00101111 \\
\hline $\mathrm{L}$ & $\mathrm{L}$ & $4 \mathrm{C}$ & 76 & 01001100 \\
\hline $\mathrm{a}$ & $\mathrm{a}$ & 61 & 97 & 01100001 \\
\hline $\mathrm{m}$ & $\mathrm{m}$ & $6 \mathrm{D}$ & 109 & 01101101 \\
\hline $\mathrm{p}$ & $\mathrm{p}$ & 70 & 112 & 01110000 \\
\hline $\mathrm{u}$ & $\mathrm{u}$ & 75 & 117 & 01110101 \\
\hline $\mathrm{T}$ & $\mathrm{T}$ & 54 & 84 & 01010100 \\
\hline $\mathrm{e}$ & $\mathrm{e}$ & 65 & 101 & 01100101 \\
\hline $\mathrm{r}$ & $\mathrm{r}$ & 72 & 114 & 01110010 \\
\hline $\mathrm{a}$ & $\mathrm{a}$ & 61 & 97 & 01100001 \\
\hline $\mathrm{s}$ & $\mathrm{s}$ & 73 & 115 & 01110011 \\
\hline $\mathrm{O}$ & $\mathrm{O}$ & $4 \mathrm{~F}$ & 79 & 01001111 \\
\hline $\mathrm{n}$ & $\mathrm{n}$ & $6 \mathrm{E}$ & 110 & 01101110 \\
\hline
\end{tabular}

Setelah pengiriman data dilakukan dari smartphone ke NodeMCU maka akan ada feedback atau balasan dari NodeMCU ke smartphone yaitu "Lampu Teras Telah Hidup". Pengiriman data kembali ke smartphone biasanya membutuhkan waktu beberapa detik saja 
tergantung kecepatan jaringan internet itu sendiri. Tetapi jika balasan pengiriman data tidak muncul maka dapat dipastikan terjadi kesalahan pada sistem. Berikut ini adalah tabel feedback konversi nilai dari data "Lampu Teras Telah Hidup".

Tabel 2 Konversi Nilai Dari Teks "Lampu Teras Telah Hidup"

\begin{tabular}{|c|c|c|c|c|}
\hline \multirow{2}{*}{ Karakter } & \multicolumn{4}{|c|}{ Konversi Nilai } \\
\hline & ASCII & Hexadesimal & Desimal & Biner \\
\hline L & L & $4 C$ & 76 & 01001100 \\
\hline a & a & 61 & 97 & 01100001 \\
\hline $\mathrm{m}$ & $\mathrm{m}$ & $6 \mathrm{D}$ & 109 & 01101101 \\
\hline$p$ & $p$ & 70 & 112 & 01110000 \\
\hline $\mathrm{u}$ & u & 75 & 117 & 01110101 \\
\hline $\mathrm{T}$ & $\mathrm{T}$ & 54 & 84 & 01010100 \\
\hline e & e & 65 & 101 & 01100101 \\
\hline$r$ & $r$ & 72 & 114 & 01110010 \\
\hline a & a & 61 & 97 & 01100001 \\
\hline $\mathrm{s}$ & s & 73 & 115 & 01110011 \\
\hline $\mathrm{T}$ & $\mathrm{T}$ & 54 & 84 & 01010100 \\
\hline e & e & 65 & 101 & 01100101 \\
\hline 1 & 1 & $6 \mathrm{C}$ & 108 & 01101100 \\
\hline a & a & 61 & 97 & 01100001 \\
\hline $\mathrm{h}$ & $\mathrm{h}$ & 68 & 104 & 01101000 \\
\hline $\mathrm{H}$ & $\mathrm{H}$ & 48 & 72 & 01001000 \\
\hline i & $\mathrm{i}$ & 69 & 105 & 01101001 \\
\hline$d$ & d & 64 & 100 & 01100100 \\
\hline u & $\mathrm{u}$ & 75 & 117 & 01110101 \\
\hline$p$ & $p$ & 70 & 112 & 01110000 \\
\hline
\end{tabular}

Sebelum melakukan perancangan sistem dibuatlah diagram blok yang akan menjelaskan aliran input, proses dan output. Seperti pada gambar 3 dibawah.

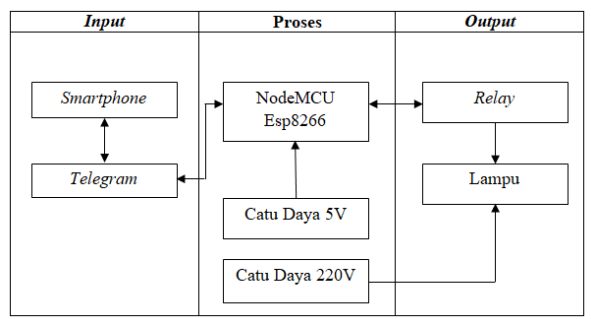

Gambar 3 Diagram Blok Sistem 
Pada gambar 3 menggambarkan suatu konfigurasi rancangan sistem alat. Terdapat beberapa blok yang bertugas dengan fungsinya masing-masing yaitu sebagai berikut :

1. Smartphone

Smartphone berfungsi sebagai media inputan.

2. Telegram

Telegram berfungsi sebagai platform untuk aplikasi Os Mobile yang bertujuan untuk kendali module.

3. NodeMCU Esp8266

NodeMCU Esp8266 berfungsi sebagai penerima sinyal wifi dan penyimpanan program. Perintah akan diterima oleh NodeMCU Esp8266 dari aplikasi telegram untuk kendali lampu dan mengirim kembali notifikasi lampu telah hidup atau mati ke aplikasi telegram.

4. Catu Daya 5V

Catu daya 5Vdisini dimaksudkan catu daya yang digunakan untuk nodeMCU Esp8266 dan relay.

5. Relay

Relay berfungsi disini sebagai saklar mekanik untuk membuka dan menutup kontak yang akan digunakan untuk memutus dan menyambungkan tegangan yang akan mengalir ke lampu. Relay akan menerima perintah dari NodeMCU Esp8266 untuk menghidupkan atau mematikan lampu.

6. Lampu

Lampu berperan sebagai output akhir. Dalam hal ini kendali lampu diatur dari nodeMCU

Esp8266 setelah menerima perintah.

Flowchart merupakan bagan yang menunjukkan alur kerja atau apa yang sedang dikerjakan didalam sebuah sistem secara keseluruhan dan menjelaskan urutan dari prosedurprosedur yang ada didalam sistem. Flowchart akan memberikan gambaran aliran data dari setiap input, proses dan output.

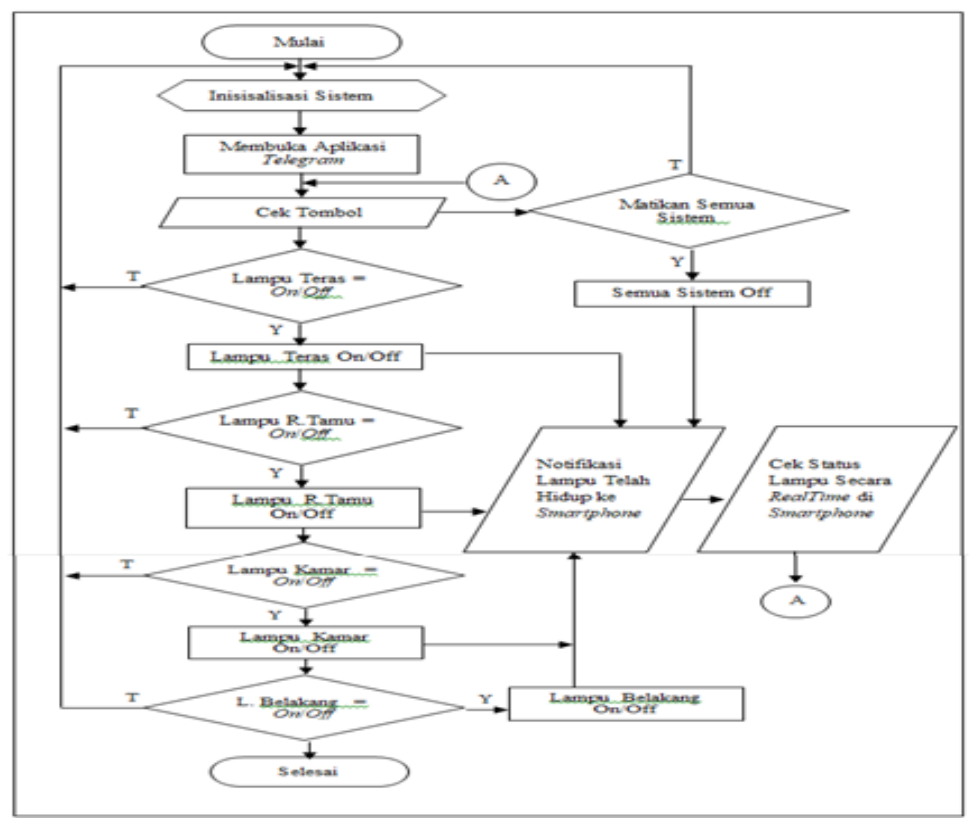

Gambar 4 Flowchart Sistem

J-SISKO TECH Vol. 3, No. 1, $2020: 32-40$ 
Pengujian sistem dilakukan untuk mengetahui fungsi dan kinerja dari keseluruhan sistem. Pengujian ini dimulai dengan melakukan pemeriksaan kerja sistem pada bagian-bagian utama hingga kinerja sistem keseluruhan. Pengujian rangkaian sistem dilakukan setelah semua komponen dan bagian-bagian terpasang utuh menjadi satu kesatuan, yaitu sistem keseluruhan pada perancangan implementasi teknik komunikasi serial Half Duplex pada kendali jarak jauh lampu ruangan rumah berbasis Internet of Things (IOT).Pengujian ini bertujuan untuk mengetahui kinerja dari relay dan aplikasi telegram. Pada sistem ini, relay berfungsi sebagai saklar otomatis berdasarkan perintah yang diberikan dan telegram berfungsi sebagai platform tempat pengiriman data teks. Setelah dilakukan pengujian, diketahui bahwa relay dan aplikasi telegram dapat berjalan dengan baik. Pada gambar 2 dibawah ini merupakan pengujian untuk memberikan perintah logika high kepada relay untuk menghidupkan salah satu lampu.

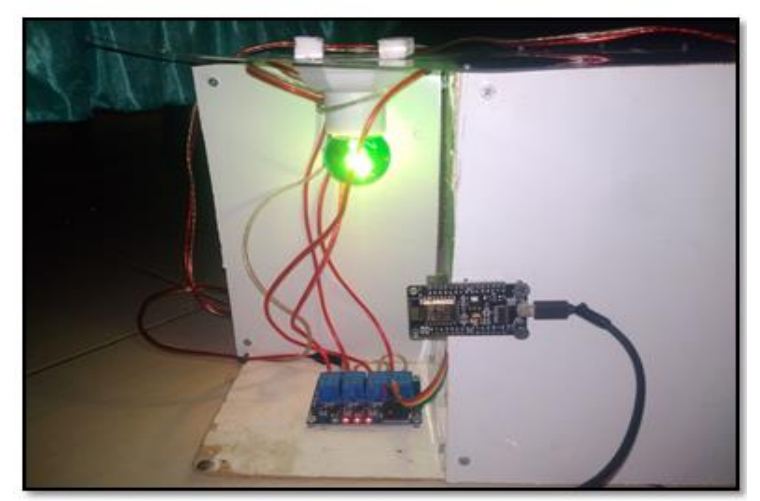

Gambar 2 Pengujian Relay

Pada gambar 3 dibawah ini merupakan pengujian untuk mengirim perintah dari telegram ke NodeMCU Esp8266 dan sebaliknya ketika menerima notifikasi dari NodeMCU Esp8266 ke aplikasi telegram.

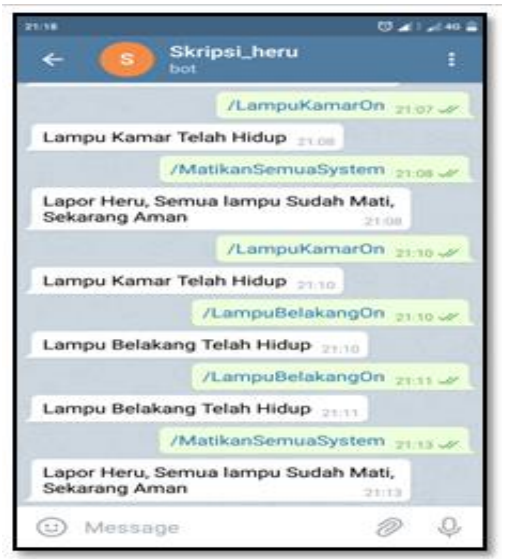

Gambar 3 Pengujian Telegram Telah Terhubung ke NodeMCU Esp8266

Pada gambar 4 dibawah ini merupakan tampilan serial monitor di arduino IDE pada saat melakukan pengiriman data teks dari telegram ke NodeMCU Esp8266 ataupun sebaliknya. 


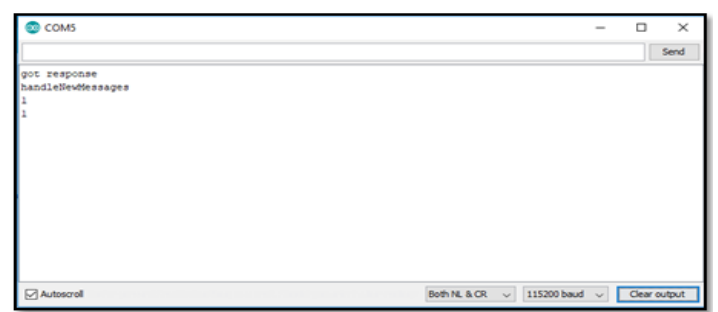

Gambar4 Tampilan Di Serial Monitor Pada Saat Pengiriman Data

Berikut dibawah ini adalah tabel pengujian keseluruhan sistem kendali jarak jauh lampu ruangan rumah berbasis internet of things yang terdiri dari beberapa pengujian pengiriman data sebagai input dan relay, lampu dan notifikasi feedback sebagai output.

Tabel 3 Pengujian Keseluruhan Sistem

\begin{tabular}{|c|c|c|c|c|c|c|c|}
\hline \multirow{2}{*}{ No. } & \multirow{2}{*}{ Pengiriman Data } & \multicolumn{4}{|c|}{ Relay } & \multirow{2}{*}{$\begin{array}{c}\text { Keadaa } \\
\mathbf{n} \\
\text { Lampu }\end{array}$} & \multirow{2}{*}{ Notifikasi } \\
\hline & & 1 & 2 & 3 & 4 & & \\
\hline 1. & /LampuTerasOn & High & - & - & - & $\begin{array}{c}\text { Hanya } \\
\text { lampu } \\
\text { teras } \\
\text { hidup }\end{array}$ & $\begin{array}{l}\text { Lampu } \\
\text { teras telah } \\
\text { hidup }\end{array}$ \\
\hline 2. & /LampuTerasOff & Low & - & - & - & $\begin{array}{c}\text { Semua } \\
\text { lampu } \\
\text { mati }\end{array}$ & $\begin{array}{c}\text { Lampu } \\
\text { teras telah } \\
\text { mati }\end{array}$ \\
\hline 3. & /LampuR.TamuOn & - & High & - & - & $\begin{array}{c}\text { Hanya } \\
\text { lampu r. } \\
\text { tamu } \\
\text { hidup }\end{array}$ & $\begin{array}{l}\text { Lampu r. } \\
\text { tamu telah } \\
\text { hidup }\end{array}$ \\
\hline 4. & /LampuR.TamuOff & - & Low & - & - & $\begin{array}{c}\text { Semua } \\
\text { lampu } \\
\text { mati }\end{array}$ & $\begin{array}{c}\text { Lampu r. } \\
\text { tamu telah } \\
\text { mati }\end{array}$ \\
\hline 5. & /LampuKamarOn & - & - & High & - & $\begin{array}{l}\text { Hanya } \\
\text { lampu } \\
\text { kamar } \\
\text { hidup }\end{array}$ & $\begin{array}{c}\text { Lampu } \\
\text { kamar } \\
\text { telah hidup }\end{array}$ \\
\hline 6. & /LampuKamarOff & - & - & Low & - & $\begin{array}{c}\text { Semua } \\
\text { lampu } \\
\text { mati }\end{array}$ & $\begin{array}{c}\text { Lampu } \\
\text { kamar } \\
\text { telah mati }\end{array}$ \\
\hline 7. & /LampuBelakangOn & - & - & - & High & $\begin{array}{c}\text { Hanya } \\
\text { lampu } \\
\text { belakan } \\
\text { g hidup }\end{array}$ & $\begin{array}{c}\text { Lampu } \\
\text { belakang } \\
\text { telah hidup }\end{array}$ \\
\hline 8. & /LampuBelakangOff & - & - & - & Low & $\begin{array}{c}\text { Semua } \\
\text { lampu } \\
\text { mati }\end{array}$ & $\begin{array}{c}\text { Lampu } \\
\text { belakang } \\
\text { telah mati }\end{array}$ \\
\hline 9. & $\begin{array}{l}\text { /HidupkanSemuaSyste } \\
m\end{array}$ & High & High & High & High & $\begin{array}{l}\text { Semua } \\
\text { lampu } \\
\text { hidup }\end{array}$ & $\begin{array}{c}\text { Semua } \\
\text { lampu telah } \\
\text { hidup }\end{array}$ \\
\hline
\end{tabular}




\begin{tabular}{|c|l|c|c|c|c|c|c|}
\hline 10. & $\begin{array}{l}\text { MatikanSemuaSyste } \\
m\end{array}$ & Low & Low & Low & Low & $\begin{array}{c}\text { Semua } \\
\text { lampu } \\
\text { mati }\end{array}$ & $\begin{array}{c}\text { Semua } \\
\text { lampu telah } \\
\text { mati }\end{array}$ \\
\hline
\end{tabular}

Setelah semua rangkaian selesai dikerjakan, maka seluruh alat akan disambungkan seperti menghubungkan relay dengan lampu, dimana lampu berfungsi sebagai output. Relay berfungsi sebagai kontrol logika yang diinginkan oleh user untuk mengendalikan lampu. User akan mengirim perintah menggunakan smartphone yang telah diinstal aplikasi telegram.
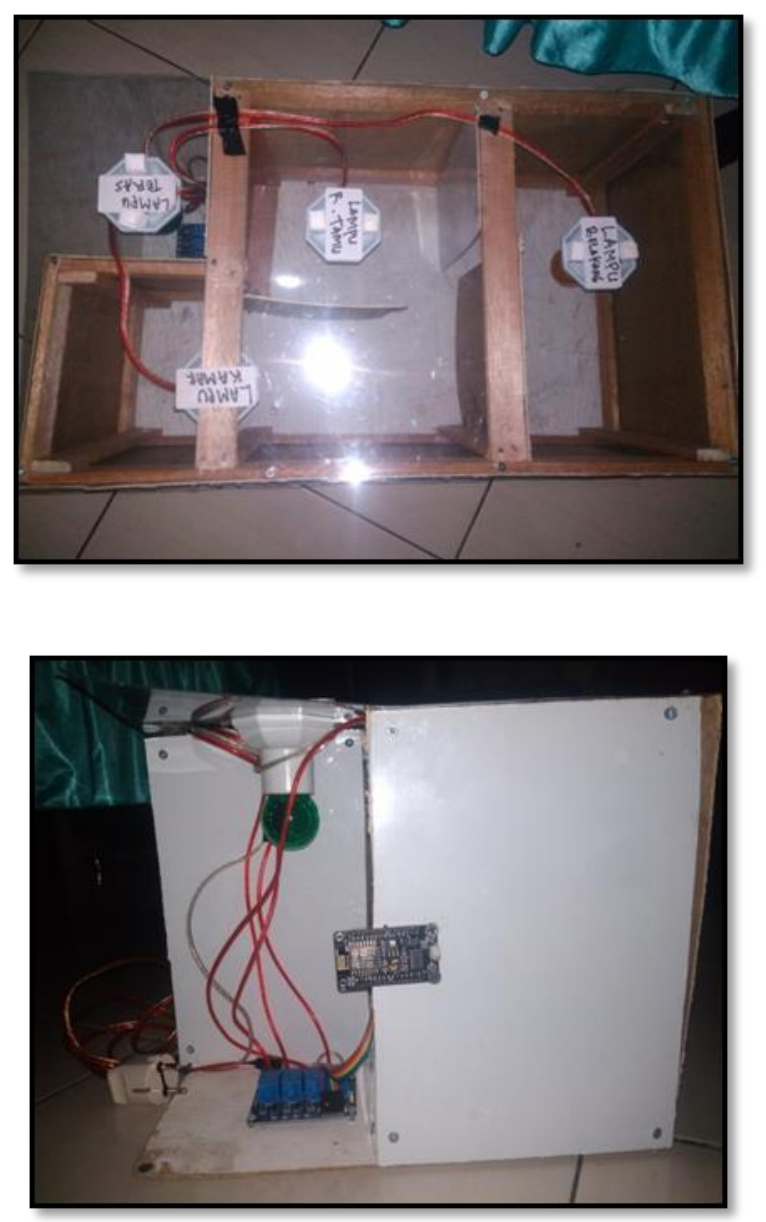

Gambar 10 Rangkaian Keseluruhan Sistem

\section{KESIMPULAN}

Adapun kesimpulan yang dapat diambil pada implementasi teknik komunikasi serial half duplex pada kendali jarak jauh lampu ruangan rumah berbasis internet of things adalah sebagai berikut

1. Implementasi teknik komunikasi serial half duplex pada kendali jarak jauh lampu ruangan rumah berbasis internet of things menggunakan aplikasi pendukung yaitu telegram dalam platform untuk pengiriman perintah dan notifikasi pesan kembali.

2. Teknik komunikasi serial half duplex dapat diimplementasikan kedalam sistem kendali jarak jauh lampu ruangan rumah untuk konversi nilai pengiriman data teks. 
3. NodeMCU Esp8266 yang berfungsi sebagai pengendali keseluruhan sistem dan menghubungkan alat ke jaringan wifi.

\section{REFERENSI}

[1] Cholis, N., \& Noortjahja, A. (2013). Pembelajaran Rangkaian Listrik Berbasis Software Proteus Sebagai Media Pembelajaran Di Man Gresik 1. Jurnal Inovasi Pendidikan Fisika, 2(3). Universitas Negri Surabaya

[2] Fatoni, A., \& Rendra, B. R. (2014). Perancangan Prototype Sistem Kendali Lampu Menggunakan Handphone Android Berbasis Arduino. Jurnal PROSISKO, 1, 23-29. Universitas Serang raya

[3] Jaya, A. (2013). Rancang Bangun Sensor Nirkabel Suhu Dan Kelembaban Menggunakan Metode Half-Duplex Pada Gudang Pabrik Tapioka. Jurnal Riset Industri, 7(3). Balai Riset Dan Standarisasi Industri Bandar Lampung

[4] Junaidi, A. (2015). Internet of Things, Sejarah, Teknologi Dan Penerapannya : Review. Jurnal IImiah Teknologi Informasi Terapan, 1(3), 62-66. Universitas Widyatama

[5] Risanty, D. R., \& Sopiyan, A. (2017). Pembuatan Aplikasi Kuesioner Evaluasi Belajar Mangajar Menggunakan Bot Telegram Pada Fakultas Teknik Universitas Muhammadiyah Jakarta (FT-UMJ) Dengan Metode Polling. Prosiding Seminar Nasional Sains Dan Teknologi 2017 (h. 1-9). Jakarta: Program Studi Teknik Informatika Fakultas Teknik Universitas Muhammdiyah

[7] Susanti, D. (2017). Eksplorasi Aplikasi Push to Talk Pada Mobile Phone. Jurnal J-Ensitec, 3(2). Universitas Majalengka

[8] Wahyudin., Wahyudi, S., \& Robbi, A. I. M. (2015). Visualisasi Masjid Agung Rangkasbitung Berbasis 3D Dengan Menggunakan Google Sketchup \& After Effect. Jurnal Prosisko, 2(2). Universitas Serang Raya

[9] Wartono., \& Sururi, N. (2018). Menentukan Titik Pemasangan Radio Wireless Untuk Link Point To Point Dengan Memanfaatkan Bot Telegram. Jurnal DISPROTEK, 9(2). Universitas Amikom Jogjakarta

[10] Wicaksono, F. M. (2017). Impelementasi Modul WiFi NodeMCU Esp 8266 Untuk Smart Home. Jurnal Teknik Komputer Unikom , 6(1), 1-6. UNIKOM Bandung 